\title{
Integrando las competencias lingüística, emocional y social y ciudadana en Educación Infantil y Primaria bajo una perspectiva lúdica: experiencia de animación a la lectura en francés (Mario Ramos) bajo un enfoque por tareas
}

\author{
Olga ELWES AGUILAR \\ Universidad de Castilla-La Mancha \\ Departamento de Filología Moderna \\ Olga.Elwes@uclm.es
}

Recibido: enero 2014

Aceptado: septiembre 2014

\section{RESUMEN}

Presentamos un monográfico sobre el autor e ilustrador infantil belga (Mario Ramos, 19582012) llevado a cabo en la Facultad de Educación de Toledo (UCLM) para los alumnos de Grado en Maestro de Educación Infantil y Primaria. La experiencia pretende desarrollar las cuatro destrezas en lengua francesa (comprensión oral y escrita, expresión oral y escrita) bajo un enfoque por tareas focalizado en tres competencias esenciales del currículo escolar: lingüística, emocional y social y ciudadana. Asimismo, reflexionamos sobre la metodología durante la puesta en escena de nuestro alumnado en cada una de las dramatizaciones en francés de los álbumes ilustrados de Ramos.

Palabras clave: competencias lingüística, emocional, social y ciudadana, enfoque por tareas, animación a la lectura, Francés como Lengua Extranjera (FLE), Mario Ramos.

Integrating linguistic, emotional and social and citizen competences in Childhood and Primary Education from a recreational perspective: a workshop of storytelling in French (Mario Ramos) trough task-based approach

\begin{abstract}
This essay aims at developing a seminar based on Mario Ramos' (1958-2012) work for children carried out in Faculty of Education (Toledo, UCLM) for Early Childhood and Primary Education pre-service students. Our experience encourages to practice the four communicative skills (oral/ written comprehension and oral/ written expression) through a task-based approach which focus on three main didactic areas from the curriculum: linguistic, emotional and social and citizen competences. In conclusion, we will also consider particularly every student's methodology in his/ her future role as a storyteller in schools.
\end{abstract}


Keywords: linguistic, emotional and social and citizen competences, task-based approach, storytelling, French as a Foreign Language (FFL), Mario Ramos.

«Intégrant les compétences linguistique, émotionnelle et sociale et citoyenne en Éducation Maternelle et Primaire sous une perspective ludique : expérience de promotion de la lecture en français (Mario Ramos) à travers l'approche par les tâches

\section{RÉSUMÉ}

Nous présentons par la suite un cours monographique sur l'auteur et illustrateur belge de littérature d'enfance et de jeunesse (Mario Ramos, 1958-2012), développé à la Faculté d'Éducation de Tolède (UCLM) par les étudiants de Formation de Maîtres. Cette expérience pratique vise à améliorer les quatre habilités communicatives en langue française (compréhension orale et écrite, expression orale et écrite) à travers l'approche par les tâches en privilégiant trois compétences essentielles dans les programmes d'enseignement: il s'agit des compétences linguistique, émotionnelle et sociale et citoyenne. De même, nous réfléchirons sur l'approche méthodologique utilisée lors des dramatisations des albums illustrés de Ramos de la part de nos étudiants: futurs enseignants dans les écoles.

Mots-clés: compétences linguistique, émotionnelle, sociale et citoyenne, approche par les tâches, promotion de la lecture, Français Langue Étrangère (FLE), Mario Ramos.

SUMARIO: 1. Introducción. 2. Desarrollo de la tarea y sus fases. 2.1. Conociendo a Mario Ramos. 2.2. Repartiendo los textos y trabajando sobre ellos. 2.3. Animando los álbumes de Mario Ramos y reflexionando sobre su potencial pedagógico. 3. Conclusiones de la experiencia. 4. Bibliografía.

\section{INTRODUCCIÓN}

Como docente de lengua francesa y su didáctica en asignaturas troncales del Plan de Estudios de Educación Infantil y Primaria en la Facultad de Educación de Toledo (Universidad de Castilla-La Mancha), así como de materias optativas que engloban aspectos más variados como metodologías de enseñanza de lenguas extranjeras y aspectos culturales, literarios y de lectura para los que serán futuros docentes en los niveles de enseñanza infantil y primaria, siempre nos interesó plantear a nuestros alumnos de Magisterio actividades realmente prácticas que pudieran resultarles significativas para su futuro laboral, más allá del mero aprendizaje de la lengua extranjera.

Introducir al alumno de Magisterio en la narración oral a través de técnicas básicas para animar cuentos (storytelling) resulta seductor y motivador en primera instancia, si bien no es tarea en absoluto sencilla. Nos topamos, en primer lugar, con los distintos caracteres de nuestro alumnado que pueden potenciar o mermar su expresividad y creatividad, considerando éste un factor humano que englobaría: la edad, la motivación, la personalidad, etc. Alumnos de Magisterio, si bien 
acostumbrados a hacer pequeñas exposiciones orales individuales o en grupo ante el resto de la clase como una de las competencias generales propias de los títulos de Grado en Maestro en Educación Infantil ${ }^{1}$ y Primaria $^{2}$, no obstante no tan familiarizados a enfrentarse a la narración oral de un cuento apoyada en las ilustraciones ante el resto de sus compañeros.

Llevados por nuestro interés personal y profesional por la obra literaria del escritor infantil Mario Ramos (Bruselas, 1958-2012) -de origen portugués aunque nacido y formado en Bélgica-, nos pareció una excelente tarea didácticometodológica introducir a nuestros alumnos, por un lado, en las técnicas básicas de la narración oral (teniendo en cuenta aspectos vocales, posturales, de control del espacio y de captación de la atención de sus futuros alumnos) y, por otro, una ocasión privilegiada para profundizar en la obra de este autor francófono a modo de seminario. Mario Ramos es ilustrador de seis álbumes infantiles (Contes et récits de León Tolstoï, 1986; Zéro de Charles Prayez, 1987; Djabibi de Rascal, 1992; Orson de Rascal, 1993; Novembre au printemps de Rascal, 1994 y Le dernier voyage de Andréa Nève, 1994) y creador al completo -tanto ilustrador como escritor- de una treintena de títulos.

De esta manera, introducimos documentos auténticos en el aula (el álbum ilustrado escrito en francés para niños francófonos), que ellos han de contar y de animar poniendo en práctica una correcta y adecuada destreza de expresión oral en francés; al mismo tiempo que sus compañeros, para seguir la narración de los textos, han de prestar atención en orden a comprender las variadas narraciones ejercitando su comprensión oral. Por lo que, en principio, este taller de animación a la lectura en francés privilegia tanto el output como el input del alumnado bajo una perspectiva lúdica.

No obstante y aunque la competencia lingüística en lengua extranjera es esencial y vertebradora en la actividad, no es la única que contemplamos en dicho seminario. Es obvio que el alumno ha de poner en práctica igualmente sus destrezas de comprensión lectora con cada uno de los álbumes asignados y, más importante si cabe, la de expresión escrita (supervisada por el docente) para adaptar

${ }^{1}$ Orden ECI/3854/2007, de 27 de diciembre, por la que se establecen los requisitos para la verificación de los títulos universitarios oficiales que habiliten para el ejercicio de la profesión de Maestro en Educación Infantil (2007). Disponible en Web: http://www.boe.es/boe/dias/2007/12/29/pdfs/A53735-53738.pdf [Consulta: 8 de febrero de 2014].

${ }^{2}$ Orden ECI/3857/2007, de 27 de diciembre, por la que se establecen los requisitos para la verificación de los títulos universitarios oficiales que habiliten para el ejercicio de la profesión de Maestro en Educación Primaria (2007). Disponible en Web: http://www.boe.es/boe/dias/2007/12/29/pdfs/A53747-53750.pdf [Consulta: 8 de febrero de 2014]. 
cada uno de los textos en su vertiente de animación oral. Es decir, en ninguno de los casos los alumnos han de leer el texto directamente en francés, pues la lectura directa puede resultar lineal y tediosa para el público infantil, sino que han de adecuarlo y adaptarlo al nivel de lengua de sus aprendientes y, en cierta manera, simplificarlo reescribiendo un output que se transforme en input comprensible para sus oyentes, teniendo en cuenta y adecuándolo oportunamente al corte de edad de los destinatarios a los que van dirigidas dichas narraciones en francés. Siguiendo las indicaciones de Andrew Wright, puede resultar que un mismo texto es susceptible de ser contado a alumnos de Infantil como de Primaria, dependiendo de los objetivos y contenidos programados así como de las actividades en torno al mismo que queramos elaborar. «No es el cuento en sí mismo el que determina el nivel, sino lo que esperamos que los niños hagan con él.» (Wright, 1996, 5). Por poner algún ejemplo ilustrativo de las obras de Ramos traducidas al español -y más conocidas por tanto-, resultaría así que su serie de lobos Soy el más fuerte (Corimbo, 2006) / Soy el más guapo (Corimbo, 2007) ${ }^{3}$ podrían servirnos para ambas etapas en función de nuestros objetivos, los contenidos programados y las actividades posteriores que queramos diseñar.

El presente trabajo, además, aspira a globalizar las tres áreas de Educación Infantil (lenguajes: comunicación y representación, conocimiento del entorno y conocimiento de sí mismo y autonomía personal, así como las del currículo de Educación Primaria a través de sus competencias lingüística, emocional y social y ciudadana) según los Decretos Ley 67/ 2007 de 29 de mayo y 68/ 2007 de 29 de mayo, respectivamente, de nuestra Comunidad Autónoma. La lengua extranjera francés es esencial y vehicular en la actividad, pero el enfoque por tareas utilizado sobrepasa lo meramente lingüístico con una clara intencionalidad de reflexión metalingüística, pero también didáctico-metodológica en cuanto que requiere a nuestros alumnos la programación de una actividad de lectura a priori lúdica, pero que comporta igualmente una clara secuenciación didáctica que todo maestro debería conocer y manejar a la hora de contar un cuento en clase. En este sentido, participamos del enfoque por tareas en la enseñanza de lenguas extranjeras llevado a cabo en las últimas décadas en nuestro ámbito de estudios universitarios superiores (Candlin, 1990; Estaire y Zanón, 1990; Esteve, Arumí y Cañada, 2005 y Estaire, 2011, entre otros). Este trabajo, pues, pretende compartir nuestra puesta en práctica y resultados de la experiencia basada en dicho enfoque a través de un taller de animación a la lectura en francés realizado durante la asignatura "Lengua, Cultura y Literatura francesas" para alumnos de $4^{\circ}$ curso de Educación Infantil y

${ }^{3}$ Premio de los Niños 2007 de la librería "Los Portadores de Sueños", Zaragoza. Revista Babar (5 de abril de 2008), disponible en Web: http://revistababar.com/wp/soy-el-msguapo-premio-de-los-nios-2007-de-la-librera-los-portadores-de-sueos/ [Consulta: 8 de febrero de 2014]. 
Primaria pertenecientes a la mención cualificadora "Lengua, Lectura y Multiculturalidad", exclusivamente ofertada en la Facultad de Educación del Campus de Toledo (Universidad de Castilla-La Mancha).

\section{DESARROLLO DE LA TAREA Y SUS FASES}

Esgrime José Morais en El arte de leer cuando se refiere a álbumes ilustrados que "el primer paso hacia la lectura es oír los libros. Oír la lectura de otro cumple una triple función: cognitiva, lingüística y afectiva" (Morais, 1994, 150). Basándonos en esta reveladora afirmación del estudioso, nuestro objetivo de partida es convertir a nuestros alumnos en narradores de historias dejando así pasar también a nuestras aulas de Magisterio tanto el elemento lúdico como la afectividad.

En cuanto a su temporalización y a las lenguas manejadas, hemos de decir que esta actividad está programada para un mes ( 8 sesiones de 2 horas cada una) en sus distintas etapas o fases y que las lenguas utilizadas son dos: el francés para la narración oral de las obras asignadas y el español para la explicación y justificación didáctico-metodológica en torno a las mismas. Haciéndonos eco de la cita anterior, esta actividad de animación a la lectura aspira, por tanto, a combinar e integrar los siguientes parámetros:

i. El lingüístico: poniendo en práctica la lengua francesa en sus cuatro destrezas.

ii. El cognitivo: ejercitando la autorreflexión por parte de nuestro alumnado para hacerles conscientes de sus fortalezas o debilidades didácticas, así como de sus aspectos de mejora.

iii. Y el afectivo: identificando los valores expuestos en cada una de las obras en orden a conectarlos con las competencias social y ciudadana y emocional del vigente currículo escolar.

\subsection{Conociendo a Mario Ramos}

De manera general, los alumnos de Magisterio desconocen a Mario Ramos que, aunque ha sido profusamente traducido a veinte lenguas incluido el español, no es aún un autor infantil bastante leído en nuestros centros escolares. Desafortunadamente, la crítica literaria infantil tampoco le ha dedicado estudios monográficos hasta la fecha, a pesar de haber sido galardonado con los premios "Québec/ Wallonie-Bruxelles de Littérature de Jeunesse" en 2001 por su sorprendente e irónico Le roi est occupé (Ramos, 1998b) y, en el ámbito español, con el III Premio Libro Kirico en $2012^{4}$ por el subversivo a la par que tierno $E l$ secreto de Luis (Un monde de cochons: Ramos, 2005b), donde invierte el rol

\footnotetext{
${ }^{4}$ Revista Babar (3 de abril de 2013), disponible en Web: http://revistababar.com/wp/elsecreto-de-luis-de-mario-ramos-iii-premio-libro-kirico/ [Consulta: 8 de febrero de 2014].
} 
tradicional del lobo feroz. Obra, por otro lado, continuada en uno de sus últimos títulos: L'école est en feu (Ramos, 2012b), donde aborda tangencialmente el actual panorama de desempleo. En nuestra opinión, el autor belga para niños despliega en sus textos e ilustraciones un variado universo de ficción ofrecido a los más pequeños mediante temas recurrentes de calado universal: amor/ amistad, problemática del poder/ crítica a la autoridad, diversidad/ identidad, colaboración/ competición, tradición/ modernidad, conflictiva relación padres/ hijos etc. Todos ellos aderezados por la reflexión y el humor, que bien merecerían una atención más pormenorizada por parte de la crítica literaria infantil especializada.

Así pues, en la primera sesión presentaremos tanto la biografía como la bibliografia del escritor e ilustrador belga y repartiremos sus obras a los alumnos. Conviene decir en este estadio que las cuatro fuentes principales de información sobre el autor con las que contamos y de obligada consulta para nuestros alumnos son:

i. Su página web oficial (http://www.marioramos.be/).

ii. Un catálogo divulgativo sobre su obra editado por Pastel/ L'école des loisirs (Le monde de Mario Ramos, 2011), escrito a partir de una entrevista concedida por el autor a Lucie Cauwe.

iii. Varios vídeos sobre su creación de fácil acceso en la red.

iv. Y una secuenciación didáctica de C'est moi le plus fort con seis fichas de lectura para alumnos franceses de Cours Préparatoire (6-7 años), (Roques, 2005, 75-87).

La primera idea esencial que queremos que extraigan en esta primera fase de presentación del autor es que escoge a sus personajes animalizados por dos motivos esenciales: porque conectan innegablemente con el universo e intereses de los más pequeños y, por otro lado, porque se insertan en la tradición literaria de Las fábulas de La Fontaine, haciéndolos encarnar caracteres y comportamientos humanos no exentos de crítica e ironía y, por tanto, portadores de la tradicional "moraleja". Como nos justifica el propio creador en uno de los vídeos: "C'est un peu le principe de La Fontaine: on utilise les animaux pour parler des travers de l'être humain. Et puis, les animaux ont beaucoup d'humour." (Mario Ramos et le monde à l'envers, 2005).

\subsection{Repartiendo los textos y trabajando sobre ellos}

Una vez presentadas a grandes rasgos la vida y la obra del autor, procedemos a distribuir sus álbumes ilustrados entre nuestros alumnos. Dado que la asignatura de $4^{\text {o }}$ curso de mención admite alumnos de Grado de Maestro tanto de la especialidad

\footnotetext{
${ }^{5}$ Disponible en Web: http://www.marioramos.be/video.php?lg=f [Consulta : 8 de febrero de 2014].
} 
de Infantil como de Primaria, es muy importante en este paso distribuir correctamente los textos para su posterior puesta en práctica y programación. Si bien algunos títulos pueden considerarse polivalentes y adaptables en el tránsito de edades entre alumnos pre-lectores (etapa de Infantil, 3-6 años) y lectores autónomos (primer ciclo de Primaria, 6-8 años), conviene ser hábiles en la adjudicación de los títulos para que nuestros alumnos los adecúen al nivel donde trabajarán en un futuro. Así, podríamos clasificar los álbumes de Mario Ramos para ser explotados en dichos niveles educativos de la siguiente manera:

i. Educación infantil: Au lit, petit monstre! (1996), Moi pas/ moi aussi (L'éléphant, Le mouton, Le chien, Le singe et moi, 1997), Quand j'étais petit (1997), Maman! (1999), Je ne suis pas une souris (2002), Tout en haut (2005), Loup, loup, y es-tu? (2006), Le roi, sa femme et le petit prince (2008), Le code de la route (2010) y Mon ballon (2012).

ii. Educación primaria: Le petit soldat qui cherchait la guerre (1998), Valentin la terreur (2000), La princesse Grenouille (2003), Mon oeil! (2004), Un monde de cochons (2005), Emily \& Alligator (2007), Le plus malin (2011) y L'école est en feu (2012).

iii. Polivalentes y adaptables: Le mode à l'envers (1995), Le roi est occupé (1998), Roméo et Juliette (1999), Nuno, le petit roi (2000), C'est moi le plus fort (2001), C'est moi le plus beau (2006), Le loup qui voulait être un mouton (2008), Après le travail (2009), Arrête de faire le singe! (2010), La peur du monstre (2011) y Le petit Guili (2013).

Nuestra distribución no es en absoluto aleatoria y no tenemos suficiente espacio aquí para justificar los contenidos lingüísticos que pretendemos abordar en cada uno de los textos de Ramos. Simplemente, nos gustaría señalar cómo los álbumes distribuidos en la etapa de Infantil constan de un vocabulario más sencillo o incluso sin texto como son los casos de Quand j'étais petit (1997) y Le code de la route (2010). Estos dos álbumes sin texto pondrán al alumno de lengua extranjera francés en una situación de creación total del discurso del relato, por lo que aquí no procede la adaptación sino la expresión escrita integral en lengua extranjera a partir de las imágenes. Por experiencia, podemos afirmar que les resulta más difícil crear a partir de la imagen ilustrada que adaptar el texto a partir del original de Ramos.

En cuanto a la clasificación de los álbumes de Primaria, el vocabulario es más complejo (Mon oeil aborda, por ejemplo, distintas frases hechas a partir de la palabra/ imagen "ojo"), los tiempos verbales más variados (podemos incluso encontrar passé simple en Le petit soldat qui cherchait la guerre), las imágenes

\footnotetext{
${ }^{6}$ Lamentamos no incluir en este estudio monográfico el único título que no hemos manejado por encontrarse descatalogado: Un cadeau fabuleux (2001).
} 
más oníricas (es el caso de Valentin la terreur, álbum en blanco y negro ${ }^{7}$ traducido con bastante éxito al japonés y coreano); pero, sobre todo, dichos títulos van a aportar una dosis de reflexión a los más pequeños. Pongamos como ejemplo Emily \& Alligator: un libro de cruel desenlace que nos hace reflexionar sobre la responsabilidad en el cuidado de nuestras mascotas. Podemos afirmar que con estos títulos el autor atiende ya menos al receptor infantil pre-lector y lo va sumergiendo, con una dosis de ternura y otra de realidad, en el universo de los adultos y de la responsabilidad de nuestros actos.

Personalmente, preferimos trabajar con los álbumes que hemos clasificado como "polivalentes y adaptables" por dos razones esenciales. Porque cualquiera de nuestros alumnos es un buen destinatario y porque admiten varias lecturas: la del pequeño pre-lector que fija su atención más en la historia y las imágenes, y la del lector autónomo que, además de lo anterior, puede abstraer el tema y apreciar el mensaje que Mario Ramos pone en marcha a través de texto e imagen en cada uno de sus álbumes. Por poner un ejemplo: Roméo et Juliette, a través de esta historia de amor entre un elefante y una ratita, no sólo no penaliza sino que normaliza el clásico tema del amor imposible tal y como reza su última frase: "Ils ne se quittaient plus parce qu'ils étaient bien ensemble, tout simplement." (Ramos, 1999b, 28). No nos gustaría abordar aquí el concepto tradicional de "moraleja" propiamente dicho, aunque sí señalar un potente mensaje del autor que como docentes nos resulta muy productivo identificar para el tratamiento de las competencias social y ciudadana (el respeto al otro) y emocional (expresar los sentimientos) de nuestro alumnado. Quizá por esta riqueza y por sus distintos niveles de lectura, la tercera clasificación (iii.) nos resulta más atractiva $\mathrm{y}$, previsible e igualmente, también a los alumnos de Infantil y Primaria.

Una vez distribuida la obra del genial escritor infantil, es la hora de dar las instrucciones claras y precisas sobre la tarea a realizar: cada uno de los alumnos tendrá que hacer el siguiente trabajo con el texto adjudicado. Por un lado, una adaptación en lengua francesa del mismo (comprensión y expresión escritas) y, por otro, una programación de aula a partir del álbum ilustrado seleccionado. Para facilitar al gran grupo la homogeneidad del trabajo de secuenciación didáctica resultante de la tarea, facilitamos a los alumnos de Magisterio el siguiente guión:

i. Ficha técnica del libro: autor, título, editorial, (número de edición), año de publicación, país de publicación, lengua original.

ii. Breve resumen.

iii. Tema de la obra.

iv. Destinatarios.

7 “J'ai toujours considéré le noir et le blanc comme les plus belles couleurs. Depuis longtemps, je voulais faire un livre dans ces dominantes. La nuit, l'imagination s'emballe, ça fait rêver. C'est fascinant et ça fait un peu peur. " (Le monde Mario Ramos, 2011, 24). 
v. Breve justificación de la programación.

vi. Temporalización.

vii. Objetivos.

viii.Contenidos.

ix. Tabla de competencias.

$\mathrm{x}$. Actividades.

xi. Evaluación.

xii. Breve conclusión.

xiii.Bibliografía.

xiv.Anexos.

A partir de este momento, nuestros alumnos han de trabajar de manera autónoma con nuestra presencia en el aula como mero apoyo o guía. La temporalización de este trabajo tutorizado de manera individual o por parejas suele llevarnos 4 sesiones de 2 horas cada una hasta la completa supervisión del trabajo de todos los alumnos. La experiencia de este seminario impartido en dos ocasiones en la Facultad de Educación de Toledo (cursos académicos 2012-2013 y 20132014), nos lleva a afirmar que las mayores dificultades se encuentran en la adaptación del texto a un francés comprensible para niños sin apenas conocimientos previos de esta lengua extranjera (input), así como en su correcta y fluida puesta en práctica fonética (output). Por tanto, en el plano meramente lingüístico y de contenidos han de extraer el campo semántico privilegiado en cada una de las obras y abordarlo con estrategias metodológicas pero sin romper "la magia del cuento", como nos advierte Wright en su obra Cuenta-cuentos:

Si el profesor utiliza los cuentos exclusivamente para fines gramaticales o para practicar cierto vocabulario o funciones, los alumnos pueden perder su fe en el profesor y en lo que él o ella quieren decir con la palabra "cuento". ¡Cuando se centre en aspectos lingüísticos tenga cuidado de no estropear la magia del cuento! (Wright, 1996, 8).

\subsection{Animando los álbumes de Mario Ramos y reflexionando sobre su potencial pedagógico}

Si bien somos conscientes de que no debemos romper "la magia del cuento" como espacio de ficción y de disfrute (dimensión lúdica), tampoco podemos olvidar que somos docentes y que estamos programando actividades con criterios metodológicos (dimensión pedagógica). Por lo que, siguiendo el modelo de Ellis y Brewster (2002) en esta tarea de narración oral o storytelling, hemos hecho hincapié en el punto $\mathrm{x}$ del esquema anterior (actividades), teniendo en cuenta los tres estadios por los que han de pasar los alumnos en cada una de sus animaciones: 
i. Actividades previas (pre): motivación, lluvia de ideas, presentación de flashcards con el léxico y los personajes de la narración, preguntas colectivas en la asamblea etc.

ii. Actividad en sí o narración del álbum ilustrado seleccionado (while): teniendo en cuenta el espacio, el material, el cuerpo, la voz, la luz, la expectación, las interrupciones voluntarias para trabajar la producción oral etc.

iii. Post-actividades (post): de naturaleza artístico-cultural fundamentalmente, que recojan o engloben tanto los objetivos generales como nuestros objetivos lingüísticos específicos (fonéticos, léxico-semánticos y estructurales).

Durante la última semana del seminario, pues, llega el momento de disfrutar de la experiencia, dado que todos seremos espectadores de esta sesión de cuentacuentos de toda la obra de Mario Ramos. Pero al mismo tiempo y tras la puesta en escena de cada una de las obras asignadas, el alumno expondrá su programación en torno al álbum o álbumes adjudicados. Al finalizar su exposición oral, se dará paso a la opinión del gran grupo, momento en que podrán comentar, debatir o ampliar con otras ideas o actividades las anteriormente propuestas por sus compañeros. El profesor ha servido de guía a lo largo de todo el proceso pero, si algún aspecto importante hubiera quedado desatendido, es el momento, tras la intervención del alumno concreto y de la opinión del gran grupo, de aportar o reforzar con su opinión y experiencia todo el potencial lúdico a la par que didáctico que nos ofrece cada uno de los álbumes ilustrados de Mario Ramos.

De manera general, cabe también señalar en este punto que los alumnos de Infantil y de Primaria son generalmente muy originales y creativos en la fase de elaboración de actividades previas y posteriores a la dramatización del cuento, dado que a lo largo de otras asignaturas vinculadas a las áreas de plástica, música, educación física o lengua (literatura infantil y juvenil) han tenido que poner en marcha y desarrollar en cursos anteriores su competencia artístico-cultural como otra de las esenciales de ambos títulos:

i. Infantil: Conocer y utilizar canciones para promover la educación auditiva, rítmica y vocal./ Saber utilizar el juego como recurso didáctico, así como diseñar actividades de aprendizaje basadas en principios lúdicos./ Elaborar propuestas didácticas que fomenten la percepción y expresión musicales, las habilidades motrices, el dibujo y la creatividad. (Orden ECI/3854/2007).

ii. Primaria: Fomentar la lectura y animar a escribir./ Desarrollar y evaluar contenidos del currículo mediante recursos didácticos apropiados y promover las competencias correspondientes en los estudiantes./ Comprender los principios que contribuyen a la formación cultural, personal y social desde las artes./ Conocer el currículo escolar de la educación artística, en sus aspectos plástico, audiovisual y musical./ Adquirir recursos para fomentar la 
participación a lo largo de la vida en actividades musicales y plásticas dentro y fuera de la escuela. (Orden ECI/3857/2007).

\section{CONCLUSIONES DE LA EXPERIENCIA}

Personalmente, hemos tenido la oportunidad de contar algunos cuentos de Mario Ramos en escuelas y bibliotecas y, por esta razón, decidimos llevarlo a nuestra aula de la Facultad con un resultado fascinante y motivador en el alumnado de Magisterio. No es éste el lugar de hacer un estudio temático de su obra sino de poner de relieve su potente imaginario plástico y literario así como sus vertientes didáctica y reflexiva. Conviene recordar de nuevo que nos encontramos ante un caso poco habitual de autor e ilustrador al mismo tiempo, lo cual no dificulta el trasvase habitual del texto literario a la imagen plástica. Más bien al contrario: lo complementa y enriquece, dado que la palabra y la mano que dibuja parten de la misma persona. Son los casos asimismo de otros grandes autores e ilustradores infantiles: Satoshi Kitamura, Eric Carle, David McKee, Anthony Browne así como de sus admirados Tomi Ungerer y Maurice Sendak. El proceso de creación de Mario Ramos, tal y como nos confiesa en la entrevista, surge casi siempre de la imagen, dadas su formación en ilustración gráfica y su experiencia en el estudio La Cambre, dirigido por Luc Van Malderen: 'Le dessin m'a toujours fasciné, parce qu'il permet de raconter des histoires. Pour moi, un bon dessin, c'est d'abord une idée. Il induit un avant et un après. Il fait rire. Il fait réfléchir." (Le monde de Mario Ramos, 2011, 9). Sin lugar a dudas, estas dos últimas frases resumen a la perfección la poética de su obra gráfica y literaria porque Mario Ramos siempre pretendió deliberadamente hacer reír y reflexionar a niños y grandes. De ahí, que sus textos nos hayan servido a la perfección para integrar y conectar las competencias social y ciudadana y emocional con la estrictamente lingüística.

Rescatando aquí, para finalizar, a muchos de sus personajes principales, vemos en primer lugar cómo el ratón Rémy (Le monde à l'envers) se siente distinto hasta que comprende que puede ser divertido ver el mundo al revés. Como los seres humanos, sus lobos (C'est moi le plus fort, C'est moi le plus beau y Le plus malin) están plagados de defectos: la crueldad, la arrogancia, la cobardía, el ridículo pero también son osados (Le loup qui voulait être un mouton); incluso pueden llegar a ser víctimas de la discriminación (Un monde de cochons) y de la miseria (L'école est en feu). Por el contrario -y de ahí su tema recurrente de la subversión-, sus cerditos pueden ser crueles con los lobos (Un monde de cochons), hasta que se ven obligados a convivir y a hacerse amigos. El mono rebelde de Arrête de faire le singe! no está enfermo: simplemente busca el reconocimiento de sus padres y su lugar en el mundo hasta que lo halla en un circo. En la selva, el pequeño león Nuno ha de adquirir una responsabilidad de poder para la que aún no está preparado, al 
igual que el pájaro Guili ${ }^{8}$ y el rey que está siempre "ocupado" ante sus súbditos hacen que nos replanteemos las relaciones de poder y sus conflictivas paradojas. Romeo y Julieta se aman a pesar de sus diferencias y de convertirse ambos en el hazmerreír de la manada de elefantes en una preciosa historia de superación de la timidez ("Les autres l'appelaient "Tomate" et ça le faisait encore plus rougir.", Ramos, 1999b, 9) y del "qué dirán". El pequeño oso de La princesse Grenouille descubre que, en ocasiones, las ranas del estanque también pueden ser princesas. La cebra Valentina tiene miedo a la oscuridad aunque resulta ser más valiente de lo que ella pensaba, y también el monstruito Pocholon, pues todas las noches acude una niña rubia a asustarle. Hermosos ejemplos estos tres últimos de la ya señalada tendencia a la subversión en la obra de Ramos.

El niño de Maman! tiene miedo de una araña en la pared de su habitación, mientras que nosotros descubrimos en cada página todo un zoológico en su hogar, aprendiendo subsidiariamente a contar del 1 al 10 en francés. Emily aprende con dureza que, si no cuidamos a las mascotas amigas, pueden desaparecer irremediablemente de nuestras vidas para siempre. Los animales de Tout en haut se dan cuenta de que no es lo mismo competir que cooperar, mientras que los de Après le travail disfrutan de su ocio tras el trabajo; salvo el gato Sacha, que pasa en el parque los lunes al sol porque en la actualidad se ha quedado en el paro ("Après le travail, Sacha, le chat, partage son repas avec les petits oiseaux. Sacha est demandeur d'emploi, depuis que son patron s'est débarrassé de lui pour raison économique.", Ramos, 2009, 36). Mario Ramos, pues, no enmascara ni edulcora la realidad: se la presenta desnuda -y en ocasiones cruda- al público infantil y adulto, pero siempre con una brizna de belleza y de esperanza ("Après le travail, Simon, le lion, s'émerveille devant le coucher du soleil. Demain est un autre jour." Ramos, 2009: 40). De ahí, la razón de nuestra fascinación por el escritor belga en cuanto a la riqueza de sus distintos niveles de lectura:

Un bon livre c'est d'abord une bonne histoire. Le texte et les dessins sont intimement liés, les deux racontent l'histoire. Sans oublier l'humour (la politesse du désespoir). Je recherche la simplicité (qui demande parfois beaucoup de travail). L'album pour enfants parle aussi aux adultes, d'où

${ }^{8}$ Le petit Guili (2013) es ya una obra póstuma. Mario Ramos fallece prematuramente el 16 de diciembre de 2012. Vid. CATINCHI, Philippe-Jean (2012) : "Mario Ramos, figure de la littérature jeunesse" [en línea]. Le monde, 21 de diciembre de 2012. http://www.lemonde.fr/disparitions/article/2012/12/21/mario-ramos-figure-de-la-litteraturejeunesse_1809466_3382.html, [Consulta: 8 de febrero de 2014]. 
l'importance des différents niveaux de lecture. De toute façon, un enfant comprend toujours beaucoup plus que ce qu'on croit. ${ }^{9}$

Pero también Mario Ramos es heredero de la tradición popular al recrear y transformar canciones y juegos infantiles franceses (Loup, loup, y es-tu?, Le roi, sa femme et le petit prince y Mon ballon ${ }^{10}$, aportando así su singular impronta de humor ("la politesse du désespoir", en sus propias palabras) y atreviéndose incluso una y otra vez con Caperucita roja en sus más recientes títulos Le code de la route, Le plus malin y Mon ballon. Porque quizá como artista se haya sentido en el derecho y en la obligación de revisitar los clásicos y transformarlos desde su personal y coetánea óptica, sumada al respeto por el canon infantil tradicional (Perrault en este caso).

En otro momento cabría hacer un estudio de la intertextualidad de Mario Ramos respecto a su propia obra y a la de sus ilustradores de cabecera: la influencia de Saul Steinberg, Tomi Ungerer (Arrête de faire le singe! Ramos, 2010b, 12) y Maurice Sendak (Au lit, petit monstre! Ramos, 1996, 16). Aquí simplemente hemos pretendido que nuestros alumnos conozcan a este gran escritor e ilustrador francófono para mejorar su nivel de francés a través de documentos auténticos, para ejercitar su comprensión y expresión tanto escrita como oral en lengua francesa, para saber cómo enfrentarse a la narración y dramatización de un álbum ilustrado y para aprender a programar didáctica y metodológicamente los contenidos de un álbum ilustrado en lengua materna o extranjera cuando en el futuro lo lleven a sus aulas. Pero, por encima de todo, hemos pretendido disfrutar con temas atemporales y universales encarnados en texto e imagen a través de la poética, subversiva e irónica obra de Mario Ramos.

En conclusión, en los aparentemente ingenuos álbumes infantiles del autor belga vemos retratado a través de personajes animalizados nuestro mundo de niños y adultos como un espejo donde se reflejan muchas de las grandes verdades e interrogaciones del ser humano: miedos y defectos, pero también virtudes y esperanzas. Nosotros tenemos igualmente la esperanza de que, tras este taller monográfico en francés sobre Mario Ramos, los alumnos de Grado de Maestro en Educación Infantil y Primaria hayan aprendido que ellos también están llamados

9 Mario Ramos et le monde à l'envers (2005). Disponible en Web: http://www.marioramos.be/video.php?lg=f [Consulta: 8 de febrero de 2014].

10 Vid. nuestro trabajo en prensa: ORTIZ, Antonia María; SALIDO, José Vicente; GUERRERO, Silvia y ELWES, Olga: "Contemos cantando: El Cancionero popular infantil como herramienta para el desarrollo de la competencia matemática", en Nuevos enfoques sobre la cultura popular en el siglo XXI, RAMÓN, María del Mar y DE GREGORIO, Eduardo (coords.), La Coruña, Editorial Netbiblo. 
profesionalmente a llevar estos trazos de verdad a sus futuras aulas con la finalidad de abrir los oídos, los ojos y la mente de los más pequeños.

\section{BIBLIOGRAFÍA}

CANDLIN, Christopher, N. (1990): "Hacia la enseñanza de lenguas basada en tareas", en CL\&E: Comunicación, lenguaje y educación, 7-8, 33-54.

CATINCHI, Philippe-Jean (2012): "Mario Ramos, figure de la littérature jeunesse" [en línea]. Le monde, 21 de diciembre de 2012. http://www.lemonde.fr/disparitions/article/2012/12/21/mario-ramos-figure-dela-litterature-jeunesse_1809466_3382.html, [Consulta: 8 de febrero de 2014].

ELLIS, Gail y BREWSTER, Jean (2002): Tell it Again! The New Storytelling Handbook for Primary Teachers Handbook. Londres, Longman/ Penguin English Photocopiables.

ORTIZ, Antonia María; SALIDO, José Vicente; GUERRERO, Silvia y ELWES, Olga (en prensa): "Contemos cantando: El Cancionero popular infantil como herramienta para el desarrollo de la competencia matemática", en Nuevos enfoques sobre la cultura popular en el siglo XXI, RAMÓN, María del Mar y DE GREGORIO, Eduardo (coords.), La Coruña, Editorial Netbiblo.

ESTAIRE, Sheila y ZANÓN, Javier (1990): "El diseño de unidades didácticas en L2 mediante tareas: principios y desarrollo", en CL\&E: Comunicación, lenguaje, $y$ educación, 7-8, 55-90. Disponible en Web: dialnet.unirioja.es/descarga/articulo/126203.pdf [Consulta: 8 de febrero de 2014].

ESTAIRE, Sheila (2011): "Principios básicos y aplicación del aprendizaje mediante tareas", en Marco ELE: Revista de Didáctica ELE, 12, 1-26. Disponible en Web: http://marcoele.com/principios-basicos-del-aprendizajemediante-tareas/ [Consulta: 8 de febrero de 2014].

ESTEVE, Olga; ARUMÍ, Marta y CAÑADA, Ma Dolors (2005): "Hacia la autonomía del aprendiz en la enseñanza de lenguas extranjeras en el ámbito universitario: el enfoque por tareas como puente de unión entre el aprendizaje en el aula y el trabajo en autoaprendizaje". Disponible en Web: http://www.publicacions.ub.es/revistes/bells12/PDF/art05.pdf [Consulta: 8 de febrero de 2014].

Le monde de Mario Ramos (2011), París, Pastel/ L'école des loisirs.

Mario Ramos et le monde à l'envers (2005). Disponible en Web: http://www.marioramos.be/video.php?lg=f [Consulta: 8 de febrero de 2014].

MORAIS, José (1994): El arte de leer, Madrid, Visor.

NÈVE, Andréa (1994) : Le dernier voyage, París, Pastel/ L'école des loisirs.

Orden ECI/3854/2007, de 27 de diciembre, por la que se establecen los requisitos para la verificación de los títulos universitarios oficiales que habiliten para el ejercicio de la profesión de Maestro en Educación Infantil (2007). Disponible en 
Web: http://www.boe.es/boe/dias/2007/12/29/pdfs/A53735-53738.pdf [Consulta: 8 de febrero de 2014].

Orden ECI/3857/2007, de 27 de diciembre, por la que se establecen los requisitos para la verificación de los títulos universitarios oficiales que habiliten para el ejercicio de la profesión de Maestro en Educación Primaria (2007). Disponible en Web: http://www.boe.es/boe/dias/2007/12/29/pdfs/A53747-53750.pdf [Consulta: 8 de febrero de 2014].

Página web oficial de Mario Ramos disponible en Web: http://www.marioramos.be/ [Consulta: 8 de febrero de 2014].

PRAYEZ, Charles (1987) : Zéro, Bruselas, Marc Bombaert Éditeur.

RAMOS, Mario (1995) : Le mode à l'envers, París, Pastel/ L'école des loisirs.

RAMOS, Mario (1996) : Au lit, petit monstre!, París, Pastel/ L'école des loisirs.

RAMOS, Mario (1997a) : Moi pas/ moi aussi (L'éléphant, Le mouton, Le chien, Le singe et moi, París, Pastel/ L'école des loisirs.

RAMOS, Mario (1997b): Quand j'étais petit, París, Pastel/ L'école des loisirs.

RAMOS, Mario (1998a): Le petit soldat qui cherchait la guerre (1998), París, Pastel/ L'école des loisirs.

RAMOS, Mario (1998b): Le roi est occupé, París, Pastel/ L'école des loisirs. RAMOS, Mario (1999a): Maman!, París, Pastel/ L'école des loisirs.

RAMOS, Mario (1999b): Roméo et Juliette, París, Pastel/ L'école des loisirs. RAMOS, Mario (2000a): Valentin la terreur, París, Pastel/ L'école des loisirs. RAMOS, Mario (2000b): Nuno, le petit roi, París, Pastel/ L'école des loisirs. RAMOS, Mario (2001) : C'est moi le plus fort, París, Pastel/ L'école des loisirs.

RAMOS, Mario (2002) : Je ne suis pas une souris, París, Pastel/ L'école des loisirs.

RAMOS, Mario (2003) : La princesse Grenouille, París, Pastel/ L'école des loisirs. RAMOS, Mario (2004) : Mon oil! París, Pastel/ L'école des loisirs.

RAMOS, Mario (2005a): Tout en haut, París, Pastel/ L'école des loisirs.

RAMOS, Mario (2005b): Un monde de cochons, París, Pastel/ L'école des loisirs. RAMOS, Mario (2006a): Loup, loup, y es-tu?, París, Pastel/ L'école des loisirs. RAMOS, Mario (2006b): C'est moi le plus beau, París, Pastel/ L'école des loisirs. RAMOS, Mario (2007): Emily \& Alligator, París, Pastel/ L'école des loisirs.

RAMOS, Mario (2008a): Le roi, sa femme et le petit prince, París, Pastel/ L'école des loisirs.

RAMOS, Mario (2008b): Le loup qui voulait être un mouton, París, Pastel/ L'école des loisirs.

RAMOS, Mario (2009) : Après le travail (2009), París, Pastel/ L'école des loisirs. RAMOS, Mario (2010a): Le code de la route, París, Pastel/ L'école des loisirs. RAMOS, Mario (2010b): Arrête de faire le singe!, París, Pastel/ L'école des loisirs. RAMOS, Mario (2011a): Le plus malin, París, Pastel/ L'école des loisirs. RAMOS, Mario (2011b): La peur du monstre, París, Pastel/ L'école des loisirs. RAMOS, Mario (2012a): Mon ballon, París, Pastel/ L'école des loisirs. 
RAMOS, Mario (2012b): L'école est en feu, París, Pastel/ L'école des loisirs.

RAMOS, Mario (2013) : Le petit Guili, París, Pastel/ L'école des loisirs.

RASCAL (1992) : Djabibi, París, Pastel/ L'école des loisirs.

RASCAL (1993) : Orson, París, Pastel/ L'école des loisirs.

RASCAL (1994) : Novembre au printemps, París, Pastel/ L'école des loisirs.

Revista Babar (5 de abril de 2008), disponible en Web: http://revistababar.com/wp/soy-el-ms-guapo-premio-de-los-nios-2007-de-lalibrera-los-portadores-de-sueos/ [Consulta: 8 de febrero de 2014].

Revista Babar (3 de abril de 2013), disponible en Web: http://revistababar.com/wp/el-secreto-de-luis-de-mario-ramos-iii-premio-librokirico/ [Consulta: 8 de febrero de 2014].

ROQUES, Jean-Luc (2005) : "C'est moi le plus fort", en La classe, CD-ROM n², $163,75-87$.

TOLSTOÏ, León (1986) : Contes et récits, Bruselas, Marc Bombaert Éditeur.

Vídeos sobre Mario Ramos de L'école des loisirs (2013) disponibles en Web: http://www.ecoledesloisirs.fr/video.php?AUTEUR=231\&rub=AUTEUR\&envoi auteur=afficher [Consulta: 8 de febrero de 2014].

WRIGHT, Andrew (1996): Cuenta-cuentos, Madrid, Oxford University Press España. 